\title{
Comparative Study of Adjustment of Visually Impaired Students
}

\author{
Pandey R. K. \\ DIET Gyanpur, Bhadohi, U.P. India
}

Copyright $\bigcirc 2018$ by authors, all rights reserved. Authors agree that this article remains permanently open access under the terms of the Creative Commons Attribution License 4.0 International License

\begin{abstract}
The present study is designed to understand the adjustment of visually impaired students, attending the special and the integrated schools. This study has been conducted on 60 visually impaired students, aged 14-16 years, attending special and the integrated setup of Varanasi city, UP, India. The method of survey has been used to elicit the information about their adjustment in the home area, school area and personal area in special and integrated set-up. Data were collected by using the adjustment scale developed and standardized by the investigator. Results indicate that there was a significant difference in the adjustment of the visually impaired students in the area of home, school and personal in special and integrated set-up.
\end{abstract}

Keywords Visually Impaired; Adjustment; Special School; Integrated School; Cognitive Development; Concept Development; Language Development; Orientation\& Mobility

\section{Introduction}

A visually impaired child is defined, in terms of visual acuity, field of vision, and visual efficiency. "Visual Ability" of the eye to see distant objects clearly is assessed using the Snellen's chart, developed by Herbart Snellen, a Dutch doctor. The chart starts with a big ' $E$ ' which a normal eye can see at a distance of $200 \mathrm{ft}$. When vision of a person is so handicapped or impaired that to see the ' $E$ ' clearly he has to come within $20 \mathrm{ft}$. of it or nearer, he is then considered legally blind. His vision is assessed as20/200 in the better eye. It simply means a legally blind person sees something at $20 \mathrm{ft}$. distance which can be seen by a normal at $200 \mathrm{ft}$. easily.

The children are partially sighted whose visual acuity does not exceed 20/70. Visual impairment is a condition in which a student's vision is deficient to such a degree that it significantly affects his school functioning. Another description may also be used to classify an individual as blind. If the visual field is severely limited, that person may be considered blind even if visual acuity is better than 20/200. This visual field limitation is often called tunnel vision. If the visual field is not greater than 20 degrees in width, the individual can still be classified as being blind even though visual acuity is not within typical range of the vision in his better eye (after correction) is less than20/70 but better than 20/200. Such children need special equipment's and are often taught in special classes or resource rooms that provide special methods and materials. In many cases they can be educated in a regular class if special material and equipments are provided. A person is defined as 'Blind' if his vision or visual acuity (after correction) is 20/200 in his better eye. This visual acuity is in general inadequate for education through the eyes, and special techniques have been devised to make possible education through tactual and auditory channels (Panda, 1997) ${ }^{[13]}$

As per The Right of Person With Disabilities Act $2016^{[27]}$

Visual Impairment is characterized by following points:-

a) "Blindness" means a condition where a person has any of the following conditions; after best correction

I total absence of sight; or

II visual acuity less than $3 / 60$ or less than $10 / 200$ (Snellen) in the better eye with best possible correction; or

III Limitation of field of vision subtending on less than 10 degree.

b) 'low vision' means a condition where a person has any of the following conditions; namely-

c) visual acuity not exceeding $6 / 18$ up to $3 / 60$ or up to $10 / 200$ (Snellen) in the better eye with best possible correction; or

d) Limitation of field of vision subtending on less than 40 degree up to 10 degree.

Educationally defined, the Visually Impaired Children are those whose visual loss indicates that they should be educated chiefly through the use of Braille tactile and auditory materials. The partially seeing child is defined as 
one who has some remaining useful visual materials as part of the educational program.

Visual impairment occurs when any part of the optical system is defective, diseased, or malfunctions. If the visual impairment is the result of a defective part (or parts), and is usually present at birth is called congenital. These include missing parts (e.g. absence of iris; absence of the eyes themselves), defective systems (e.g., dislocation of the lens; holes in the retina; drainage systems that are stopped up), and hereditary conditions (e.g., refractive errors due to eyeballs that are too short or too long; improperly shaped corneas; albinism). Diseases can be pre-natal, at birth or post-natal (e.g., damage shortly thereafter birth), or adventitious (acquired later in life) e.g. diseases that develop gradually such as diabetic retinopathy. (Panda, 1997) $)^{[13]}$

\section{Background}

Eye is a very important sensory organ which accounts for a very large fraction of total information available to a person through his senses. It has been estimated that approximately $85 \%$ information which is more than three-fourth of all learning comes through the use of the eyes. The visually impaired children have to do all their learning using their other senses which are not impaired i.e. hearing, taste, and smell, sensation or touch. Research studies show that one child out of the five has a correctible vision defect and vision defects left undetected or uncorrected for too long that may bring about failure, retardation, or other maladjustments. With the development of democracy and socialism in different countries of the world, education has been considered to be basic right of the child. This realization paves that the way for bringing the children in to mainstream. In India, disabled population has increased by $22.4 \%$ between 2001 and 2011. The number of disabled, which was 2.19 crores in 2001 , rose in 2011 to 2.68 crore -1.5 crore males and 1.18 crore females .Rural areas have more disabled people than the urban areas. In Maharashtra, Andhra Pradesh, Orissa, Jammu and Kashmir and Sikkim, the disabled account for $2.5 \%$ of the total population, while Tamil Nadu and Assam are among those where the disabled population is less than $1.75 \%$ of the total population. The growth rate of disabled population is more in urban areas and among urban females. The decadal growth in urban areas is $48.2 \%$ and 55\% among urban females. As per census 2011, 20.3\% of the disabled are movement disabled followed by hearing impaired (18.9\%) and visually impaired (18.8\%). Nearly $5.6 \%$ of the disabled population is mentally challenged. Visually impaired is considered as a low prevalence after the mentally challenged. Prevalence of disability condition exists in approximately $1.42 \%$ of $0-4$ age group; $1.54 \%$ of $5-9$, ages and $1.82 \%$ of $10-19$ age groups (Census of India$2011)^{[4]}$. The visually impaired children are nearly 2.826 million. They are of chronological age $0-14$, which constitutes 0.387 percent of school children - National Sample Survey Organization (NSSO, 2002) ${ }^{[12]}$. Thus, it is found that more than 80 percent of our visually impaired population is rural based, while educational institutes are concentrated in urban areas. Approximately five percent visually impaired children receive education, which impart smaller fraction to achieve economic independence.

\section{Impact of Visual Impairment}

Visual impairment results in several educational, social and psychological effects. The effects are both objective and subjective depending on the type and degree of visual impairment .For educational purposes, it is considered desirable to classify the nature of effects.

The objective effects of visually impairment are cognitive. As senses is the gateway to knowledge. Sensory defect in vision reduces the range and quality of cognition. Moreover vision is the most actively used sense. Lots of knowledge grows out of the visual experiences. Therefore, the resulting effects of the vision are severe.

Berthold Lowenfeld says that visual impairment "imposes three basic limitations" on the individual. i.e. (i) Restriction in the range and variety of experiences, (ii) Restriction in the ability to get about, (iii) Restriction in the control of environment and the self relation to its.

A visually impaired person can gain knowledge of the spatial qualities of objects only by touch observations. In this type of knowledge kinesthetic experiences play an important role. In order to perform any touch observations, direct contact is must with the objects to be observed. One aspect of vision, color perception, cannot be performed by any other sensory organ because it is a function of retina. Visually impaired child often gain only a partial knowledge of objects because touch requires direct contact with the objects to be observed. There is one more cause for this restriction, the sense of touch generally functions only if it is actively employed for the purpose of cognition, whereas vision is active as long as the eyes are open and the bearing functions continually unless its organ is obstructed.

The visually impaired children are not able to move around themselves. The total loss of vision makes the person dependent on his other senses, which results in increased difficulties and deceleration in getting about. Many regard this restriction as the most severe single effect of visual impairment. The limitation of a visually impaired person affects the person not only in gaining his/her opportunities for experiences but also in his/her social relations. Lack of vision limits their mobility, exposure and stimulation for gaining new knowledge. He is limited in his spontaneous decision to engage in or follow up on various pursuits of knowledge and happiness.

Mobility is the capacity or facility of movement consists 
of two components- physical locomotion and mental orientation. These two components are not separate functions but are coordinated in the actual process of getting about. Locomotion may be defined as the movement of an organism from place to place by means of its organic mechanism, and mental orientation may be defined as ability of an individual to recognize his surroundings and their Temporal and spatial relations to himself.

Visual experiences not only permit control of the environment but also the self in relation to it. It is more effective than that achieved by the other senses, either singly or in combination. Because of this reason, lack of sight causes a detachment from the physical and to some extent from the social environment. The visually impaired persons cannot inform himself at a glance of his/her situation within a given environment as the seeing persons can. Lack of visual continuity is responsible for the visually impaired child's retardation in the process of turning from the self of the outer world. In the social aspects of an individual's life, visual impairment does not essentially interfere with the communication but also affect expressive movements, whether frontal expressions or gestural behavior, because most of them acquired by visual imitation. Therefore, the visually impaired people are often apprehensive and even fearful of being watched. The detachment from the environment has many effects on the children e.g. the visually impaired children are not visually stimulated to reach out for the source of sound, tendency to immobility in young blind children etc.

Visual impairment affects the cognitive development in two ways either direct or indirect influence. Direct influence are those which result immediately from visual impairment in a cause effect relationship and which generally have a handicapping effect on the development of the individual. The indirect influence plays a vital role in cognitive development. The loss of vision tends to restrict the process of gathering, storing, retrieving and organizing information.

Visual experiences is extremely useful in building concepts and since vision plays a dominant role in cognition, the impaired child's position in this area will show specific differences as compared with sighted children. Impaired child gains knowledge of the realities around him in a different way. In developing the conceptions the totally blind persons must rely upon the use of his remaining senses. Touch kinesthetic and audition are the most important sensory avenues.

The process of concept formation is based on classification means noting similarities and disregarding insignificant differences. Classification depends on sensory experiences. And lack of these sensory experiences prohibits the process of concept formation. This is observed that the concepts received by other senses are defective. The information received by sight and touch are different. A sighted child can see anything to make his/her concept formation at a glance. But a visually impaired child makes his/her concept through part to whole. Therefore visually impaired children have some difficulty in formation of concepts.

Language development is the most important way of communication for the visually impaired child as well as sighted child. A sighted child can communicate through his/her gestures but a visually impaired child cannot do so. Because of this language development is more necessary for visually impaired child in comparison to sighted child. There is very little difference from sighted child in some areas of language development of visually impaired child. This is due to medial learning. A sighted child can see the movement of lips while other saying something and also can understand the said word using in which context, but an impaired child cannot see and cannot understand the meaning of the said word. So the visually impaired child uses the word without knowing its meaning (verbalism). Most of parents not trying to teach vocabulary do development that is based on visual experience and thus they confuse the child.

This is assumed that intellectual development develop more slowly in a visually impaired child than in sighted one. This is due to three basic restrictions on visually impaired child. The impaired child- builds tip concepts of his/her surrounding environment through remaining sense, but the information received by visual sense is extremely useful in building concepts. By the sense of touch a visually impaired child cannot make concepts of distant (building), very large (mountains), very small (ant), fragile (butterfly) and dangerous things (flame). Anyone cannot make his/her concepts of these things without visual sense. Hence these limitations make the total experience of the visually impaired child more restricted. Researchers noted that the nature of the concept that an individual acquires depend on his/her range of experience. So the concepts of a visually impaired child are in some ways more restricted than those of a sighted child. Thus the visually impaired are more dependent on second hand experiences that is conveyed by verbally transmitted information by other people

Cognitive development is the product of an interaction between individual and the environment. In lack of sensory data needed for proper cognitive development there is some difficulty for the visually impaired child. For a good type of concept formation such sensory data must be given to visually impaired child by contriving new and imaginative play situation. The visually impaired child has all the equipment for storing processing and retrieving sense data gathered from experience. All cognitive development including the concept formation is experience of interaction with the environment to take the visually impaired child to experiences that he cannot have at home or in the classroom and for making more and more interaction with the environment. To achieve this one should organize visits to museums, post offices, railway 
stations and other public places ( Mittal 2001) ${ }^{[10]}$.

Thus; aforesaid limitations delay cognitive; intellectual, language, orientation and mobility development as compared to that of sighted counterparts. Blindness always produces shock; it affects the parents and the family members, and the individual who is afflicted with it. The absorption of shock, both physical and emotional is prerequisite to adjustment to visual impairment.

\section{Review of Related Studies}

Lakshmi et.al(2009) ${ }^{[9]}$ reported that there was a significant difference in the attitude of the parents towards their visually impaired children in the area of social and emotional behaviour, sibling attitude and towards the concept of integrated education.

The good communication and positive societal interaction foster relationships and emotional adjustment, but for a visually impaired child, these channels are blocked, sometimes resulting in emotional instability Pradhan $(2010)^{[17]}$.

Chaudhary and Phogat (2010) ${ }^{[2]}$ studied adjustment of visually challenged adolescents in relation to their anxiety and degree of impairment and concluded that low anxious totally visually challenged males are better adjusted than high anxious males while there was no significant difference between low anxious females and high anxious females, low and high anxious partially visually challenged males and low and high anxious partially visually challenged females on adjustment.

Reema $(2010)^{[23]}$ conducted a study of relationship between self-concept and adjustment of visually impaired adolescents studying in inclusive and special schools. The findings of the study revealed that the development of self-concept was better in inclusive schools. It was even better in the case of male adolescent than the female ones. The relationship between self-concept and level of adjustment in the case of female adolescents was better in inclusive school settings than their male counterparts. This trend was reversed in the case of relationship between those aspects in special schools.

Were et al. (2010) ${ }^{[28]}$ studied gender differences in self-concept and academic achievement among visually impaired pupils in Kenya. A sample of 262 respondents (152 males and 110 females) was drawn from the population by stratified random sampling technique. Two instruments were used in this study: Pupils' self-concept and academic achievement test. The $t$ test was used to test the relationship between self-concept and achievement. The data was analyzed using 48. Analysis of Variance (ANOVA) structure. Results of the study revealed that there are gender differences in self-concept among visually impaired pupils. Girls scored higher than boys in self-concept and hence in achievement test.

Rani $(2010)^{[21]}$ depicted that academic anxiety of visually impaired students was positively and significantly correlated with their academic achievement. Female students were academically more anxious than their male counterparts. Moreover school setting also has significant impact on academic achievement of visually impaired students.

Rani $(2011)^{[22]}$ compared academic achievement of visually disabled students in integrated and segregated school settings. The results of the study revealed that students placed in integrated schools performed significantly better than their counterparts in segregated schools.

Daryl et al.(2012) $)^{[3]}$ reported that Adjustment to vision loss is significantly associated with depression and certain traits of personality (specifically neuroticism and conscientiousness), independent of the severity of vision loss.

Kumar and Singh $(2013)^{[8]}$ concluded that there is significant relationship between emotional intelligence and adjustment and sighted students have better intelligent and adjusted than visually impaired students.

$\operatorname{Mishra}(2013)^{[11]}$ reported that there is positive relationship between ego-strength and adjustment. He further concluded that. Ego-strength of sighted students is better than that of visually impaired. It means blindness affect ego-strength.

Pandey $(2013)^{[14]}$ reported that adjustment of visually impaired adolescence varied significantly when compared with sighted adolescence in special set up. There was significant difference in adjustment of visually impaired adolescence when compared to VI in special and that of in integrated schools. There was no significant difference in adjustment sighted adolescence and that of visually impaired adolescence in integrated set up because of similarity in environment that provide plenty of experiences for visually impaired.

Gill $(2014)^{[6]}$ investigated Emotional, Social and Educational Adjustment of Visually Handicapped Students of Special Schools students. By the application of mean, standard deviation, and t-test indicated is no significant difference between the educational, social and emotional adjustments of special school Students belonging to boys and girls.

Rajkonwar et al. (2015) ${ }^{[20]}$ studied Adjustment and Academic Achievement of Visually Handicapped School Children in Assam and the study reported that the adjustment of visually handicapped boys and girls was found similar on overall adjustment.

The study was carried out by Parua $(2015)^{[18]}$ to determine the difference in emotional development among visually impaired students studying in integrated and special schools. The results show that there is a significant difference between visually impaired students studying in integrated and special schools on emotional development in general and all the dimensions of emotional maturity scale. Further, the visually impaired students studying in integrated schools were more emotionally matured than the 
students those were in special schools.

Pant and Joshi $(2016)^{[16]}$ revealed that children with visual impairment studying in inclusive setup are more emotionally stable than the children with visual impairment studying in special school.

Singh et al.(2016) ${ }^{[26]}$ revealed that there is a significant adjustment difference between disabled children and normal children.

Dutta and Talukdar (2016) ${ }^{[19]}$ reported that majority of the students with vision impairment obtained low scores on all dimensions of self-concept, namely physical, moral, personal, family, social and academic, some students obtained normal scores in relation to family and academic self-concepts but there is no significant differences between female and male students with vision impairment across the six dimensions of self-concept and thus total self-concept.

Gahlawat $(2017)^{[7]}$ reported that on the whole, personality and mental health of visually challenged adolescents are significantly lower than their normal counterparts.

Banoo et al.(2017) ${ }^{[1]}$ revealed that emotionally, physically deformed children have better adjustment than visually impaired. Physically deformed are more adjusted at School than visually impaired children.

Visually impaired have similar needs as sighted. They continuously interact to their surroundings to satisfy their needs, it may be home, school or personal and even their own emotion. Visually impaired having limited experience and opportunity posed serious problem to adjust. Thus, for proper adjustment of visually impaired, it is essential for parents, teachers and peer groups to have positive attitude which in turn develop positive self-concept and positive attitude . Adjustment is essential for rehabilitation. To cater the needs of visually impaired children, special and integrated institutions are established.

Special Education is as a separate system of education for children with special needs. It was based on the assumption that children with disability had some special needs that could not be met in mainstream schools and therefore, they need to study in a separate school with other children having similar needs. Special school exists in the form of day or residential schools, and also special classes are attached to the mainstream schools. In residential one, a child is separated from the family and community and it is pealed institutionally with other children who have similar problems requiring specific services from staff. An alternative to residential schools was provided by a day school. The day school has the merit of keeping the child in the family and community while providing care of specially trained teacher and professionals to guide the child's educational development.

For special education some special infrastructure is needed. Also it can be included in mainstream education with some special facilities for it. Special education requires following three elements trained professionals - including teachers, educationist, and physiotherapists. Special curriculum- made for students with different disabilities. Infrastructure facilities- like building, study places, materials and equipments.

The major disadvantages of separate education in separate environment are that, the children staying away from families may find it hard to readjust to their families' peers and communities. Children usually have to leave their families and communities to stay in a residential setting because these schools are usually not available in their immediate environment.

The special schools however, have some advantages like they can play an active role in giving resource support for the mainstream schools by providing specialized services. Also since the children are taught by a specialist having expertise on specific impairments, their needs may sometimes be understood better. In special schools children grow up with their disability peers and develop a common culture. In spite of the benefits of inclusive education, if a child with disability is not getting the required resource support in the mainstream school and is not developing up to her/his potential a special school remains a viable option.

Integrated education has its roots in various movements which did not recognize segregation. Its basis is recognition of equal rights for all citizens and equally equality of educational opportunities for all children. It emphasizes on education of disabled children in general schools. Integrated education refers to education of disabled children in common with others in general schools with provision of extra help for the disabled. It refers to integration visually impaired and physically disabled children with non disabled children in regular classroom and providing specialized services to meet their special need. Integration can be of following types-

Physical integration-it involves planning for location of special programmes in schools building with regular education programmes.

Social integration-it involves planning for regular personal interaction between students who have disability and those who do not have.

Academic integration-it involves planning to ensure students with and without disability simultaneously use of school resources.

Societal integration-societal integration involves planning designed to enable students with moderate and serve disabled to work, live and spend leisure time with their fellow non disabled.

Integrated Education covers following types of disabled children-

(i) Educable mentally retarded.

(ii) Orthopedically impaired

(iii) Partially sighted

(iv) Mildly and moderately hearing impaired

(v) Learning disabled 
(vi) Blind children who have completed preparation in Braille reading and writing, orientation and mobility training.

(vii) Deaf children who have acquired communication skills and learnt speech reading.

Integrated schools are less expansive as compare to that of special schools because a special learning material and specially trained teachers are not appointed. It helps to remove inferiority complex among disabled children because It provides affection, love and respect for disabled children among normal children .And its' environment is conducive for disabled or challenged students where they not only get help from peers for learning but also get motivated for learning. Thus; integrated schools ensure social integration by providing opportunity for full participation to enjoy life without fear and anxiety among disabled children along with normal children (Singh $2010)^{[25]}$.

The adjustment of visually impair varied according to setting. The main purpose of this study was to investigate how school (special/integrated) placement influences the adjustment of visually impaired students. The present study is a humble endeavor in this respect.

\section{Objectives of the Study}

The objectives of the present study were

1. To compare the adjustment of visually impaired students in special and integrated set up.

2. To compare the home area adjustment of visually impaired students in special and integrated set up.

3. To compare the school area adjustment of visually impaired students in special and integrated set up.

4. To compare the personal area adjustment of visually impaired students in special and integrated set up.

\section{Hypotheses}

The following null hypotheses were tested during the proposed study.

h01.There is no significant difference in adjustment of visually impaired students in special and integrated set up.

H02.There is no significant difference in home area adjustment of visually impaired students in special and integrated set up.

H03.There is no significant difference in school area adjustment of visually impaired students in special and integrated set up.

H04.There is no significant difference in personal area adjustment of visually impaired students in special and integrated set up.

\section{Data Collection}

Sample-The descriptive survey method was used to collect data for present study. It comprised 60 randomly selected visually impaired students which includes 30 visually impaired students in special setting (Shri Hanuman Poddar And VidyalayaDurgakund )and that of 30 in integrated setting( JeevanJyoti Integrated Institute for Blind ) of Varanasi city UP. The adjustment scale of a Hindi version has been developed and standardized by the investigator and it is used to find out the adjustment of visually impaired students in home; school and personal area.

\section{Tools Used}

The adjustment of visually Impaired was measured by three point Likert scale developed and standardized by investigator; Pandey $(2010,2013)^{[15][14]}$. There are thirty items in this scale to measure students' adjustment in three area home; school and personal. These test items are often; seldom and never type. The reliability of the scale is established by split- half method (0.65). This reliability was established through a pilot study and was considered to be sufficient. Content validity was established by consulting the panel of expert. Thus, it is a reliable and valid test to measure adjustment of visually impaired students.

The tool consists of 30 items. The dimension of adjustment of visually impaired students having 10 items each to home, school and personal areas. There are equal numbers of positive and negative statements. For ease of scoring the response have been obtained on three levels always; seldom; and never. In case of positive statement if a respondent respond on always alternative 3 marks has assigned and for seldom and never ;2and1 marks have been assigned respectively. In case of negative statements scoring pattern is reverse that of the positive statements. A respondent can obtain maximum 90 and minimum 30 as score on this adjustment scale of visually impaired students.

\section{Statistical Analysis}

The data were analyzed using suitable statistical techniques. Mean and standard deviation were calculated for special and integrated schools administering adjustment scale. Scores were tabulated separately for each setting in the form of overall adjustment; adjustment in home; school and the personal area. ' $t$ ' test was applied to test the significance of difference between the mean scores of the special and integrated school groups, i.e. overall adjustment, adjustment of home area; school area and personal area were compared .

\section{Results and Discussion}

The results and their respective discussions are given below in a tabular form-

Objective:-1 to compare the adjustment of visually 
impaired students in special and integrated set up. The corresponding null hypothesis formulated is as follows-

"There is no significant difference in adjustment of visually impaired students in special and integrated set up".

To test this hypothesis t-test of significance of Mean difference was applied and t- value along with Mean and SD of integrated and special set up have been given in table below(Table-1)

Table 1. Mean SD and value for the Adjustment of VI Students in Special and Integrated set up.

\begin{tabular}{|c|c|c|c|c|c|}
\hline s. n. & VI Students in & $\mathbf{N}$ & Mean & SD & t- value \\
\hline 1 & Integrated & 30 & 64.50 & 4.20 & $11.77^{*}$ \\
\hline 2 & Special & 30 & 53.10 & 3.25 & \\
\hline
\end{tabular}

* Significant at .05 level

Table -1 shows that t- value of 11.77 is significant at 0.05 levels. Thus, the null hypothesis that there is no significant difference in adjustment of VI students in special and integrated set up is rejected. It means there is significant difference between adjustment of VI students in special and integrated set up. Probable reason for this result may be due to the integrated set-up having varieties of exposure compared to that of special setup which, in turn, provide better social and personal interaction. These healthy inter-personal and intra-personal experiences boost up their morale fetching good result in term of proper adjustment either at home, school or a personal area. This result is in consonance with the findings of Pandey $(2013)^{[14]} \&$ Parua $(2015)^{[18]}$.

Objective: -2 to compare the home area adjustment of visually impaired students in special and integrated set up.

The corresponding null hypothesis formulated is as follows-

"There is no significant difference in home area adjustment of visually impaired students in special and integrated set up".

To test this hypothesis t-test of significance of Mean difference was applied and t- value along with Mean and $\mathrm{SD}$ of integrated and special set up have been given in table below.(table 2)

Table 2. Mean, SD and value for the Home area adjustment of VI students in Special and Integrated Settings

\begin{tabular}{|c|c|c|c|c|c|}
\hline s. n. & VI Students in & $\mathbf{N}$ & Mean & SD & t-value \\
\hline 1 & Integrated & 30 & 22.06 & 2.37 & \multirow{2}{*}{$5.31^{*}$} \\
\hline 2 & Special & 30 & 19.16 & 1.82 & \\
\hline
\end{tabular}

* Significant at 0.05 level

Table 2 shows that $t-$ value of 5.31 which is significant at .05 level. Thus, the null hypothesis that there is no significant difference in home area adjustment of VI students in special and integrated settings is rejected. It means there exists a significant difference between home area adjustment of VI students in special and integrated settings. It may be due to the indifference of home area adjustment of VI students in special and integrated settings.
Objective:-3 to compare the school area adjustment of visually impaired students in special and integrated set up. The corresponding null hypothesis formulated is as follows-

"There is no significant difference in school area adjustment of visually impaired students in special and integrated set up".

To test this hypothesis t-test of significance of Mean difference was applied and t- value along with Mean and $\mathrm{SD}$ of integrated and special set up have been given in table below.(table 3)

Table 3. Mean, SD and value for the school area adjustment of VI students in Special and integrated Setting.

\begin{tabular}{|c|c|c|c|c|c|}
\hline S. N. & VI Students in & $\mathrm{N}$ & Mean & SD & t- value \\
\hline 1 & Integrated & 30 & 21.26 & 2.78 & $6.43^{*}$ \\
\hline 2 & Special & 30 & 17.30 & 1.90 & \\
\hline
\end{tabular}

* Significant at 0.05 level

Table 3 shows that $t-$ value of 6.43 which is significant at .05 levels. Thus, the null hypothesis that there is no significant difference in school area adjustment of VI students in special and integrated settings is rejected. It means there exists a significant difference between school area adjustment VI students in special and integrated settings.

This may be due to reason that VI adolescents in special setup, having restricted exposure hamper the self-confidence, and self-concept reduce problem solving ability and affect the adjustment process. This result is in consonance with the finding of Rukwaro,(2006 ${ }^{[24]}$. As he investigated that integrated and special schools offer different opportunities for social interaction and social experiences. The blind child who is placed in an integrated school enjoys greater social interactions and experiences as compared to the child in the special school.

Objective:-4 to compare the personal area adjustment of visually impaired students in special and integrated set up.

The corresponding null hypothesis formulated is as follows- "There is no significant difference in personal area adjustment of visually impaired students in special and integrated set up".

To test this hypothesis t-test of significance of Mean difference was applied and t- value along with Mean and SD of integrated and special set up have been given in table below(table 4).

Table 4 shows that t- value of 8.52 which is significant at .05 levels. Thus, the null hypothesis that there is no significant difference in personal area adjustment of VI students in integrated and special settings is rejected. It means that VI students in integrated set up having conducive environment for interaction; resulting greater exposure strengthen self-confidence in personal area adjustment as compared to that of the special setup. Thus, VI students are better adjusted so far as their personal adjustment is concerned in integrated setting. This result is in consonance with the finding of Daniel $(2012)^{[5]}$. He 
investigated that integrated schools offer more opportunities for interaction with other children and a favorable environment for the development of a positive self - concept. The placement of blind children in integrated schools may make them feel that they are not different from unimpaired children - a feeling that may affect their self - concept.

Table 4. Mean; SD and value for the personal area adjustment of VI students' special and Integrated Setting.

\begin{tabular}{|c|c|c|c|c|c|}
\hline s. n. & VI Students in & $\mathrm{N}$ & Mean & SD & $\begin{array}{c}\mathrm{t}- \\
\text { value }\end{array}$ \\
\hline 1 & Integrated & 30 & 21.26 & 1.99 & $8.52^{*}$ \\
\hline 2 & Special & 30 & 16.76 & 2.10 & \\
\hline
\end{tabular}

*Significant at 0.05 levels

\section{Conclusions}

The following are the conclusion regarding the study

1. Students in integrated settings were found to be better adjusted as compared to that of special setting.

2. Students in integrated settings were found to be better adjusted in home area as compared to those in special setting.

3. Students in integrated settings were found to be better adjusted in school area compared to that of special setting.

4. Students in integrated settings were found to be better adjusted in personal area as compared to that of special setting.

Aforesaid studies indicate that pupils with visual disability in integrated settings have more age appropriate behavior than those in segregated settings. Thus integrated setting was found more favorable for mainstreaming of visually impaired students as compared to that of special settings. This result is in consonance with the findings of ; Daniel (2012) Pandey (2013)\&Parua (2015). The present results also give insight to authorities working in the field of education to organize workshops, seminars, lectures and conferences on special education. Such efforts will be helpful in creating awareness among teachers, students, administrator, members of the school management committee, parents, special educators, social workers, media personnel's working in the field of special, integrated and inclusive education.

\section{Educational Implications}

The present study has its implication for teachers, educational administrators, curriculum framers and parents. The first responsibility of the parents and teachers should be to know the areas where the students lack adjustment and try to give better conditions for proper adjustment in every sphere. The school should provide facilities to visually impaired students for their better adjustment and all round development. Proper guidance and counseling services pertaining to all the three areas of adjustment should be provided to students. School environment must be cordial and congenial. There should be proper provision of co-curricular activities in the school. Parents should have knowledge of school environment and facilities before getting their wards admitted to schools. Administrators should appoint well-qualified staff. Teachers should provide congenial environment and equal opportunities to all students for exploration.

\section{Appendix}

\section{Key Words}

Visually Impaired: In an educational (functional) definition, visually impaired or totally blind are those who are so severely challenged that they must learn Braille to read and write while low vision students can still use their residual vision as a primary sense to deal with day-to-day visual demands with suitable assistive devices.

Adjustment: - Adjustment means to modification to compensate for or meet special condition. Adjustment is the process of finding and adopting modes of behavior suitable to the environment or the changes in the environment (C.V.Good 1959).In the present study only ability to adjust in home; school and personal area was taken into consideration.

Special school: A residential educational set up where visually impaired students admitted exclusively in order to cater their special needs accordingly to special curriculum by special teacher.

Integrated school: A Non-residential educational set up where visually impaired students admitted with non-disabled counterparts with little or no modification in the existing curriculum for non-disabled students taught by general teacher while the resource teacher provides them curriculum

Cognitive development: Refers to development of knowledge; skills; problem solving and dispositions which help children to think about and understand the world around them.

Concept development: Refers to basic understanding that is necessary to make sense of one's' word. This includes ideas about the self and others, objects and environment.

Language development: It is the process by which children come to understand and communicate language in early childhood.

Orientation\& Mobility: Mobility is the capacity or facility of movement consists of two components i.e. physical locomotion and mental orientation.

\section{Adjustment Scale for Visually Impaired Student}

Please listen carefully each items and whether each item 
applicable to you told it as
(1) Often
(2) Seldom
(3) Never

1 -You feel life is dull and uninteresting.
(1) Often
(2) Seldom
(3) Never

2-You generally uninterested in the subject taught in your class.
(1) Often
(2) Seldom
(3) Never
3-You worry unnecessary.
(1) Often
(2) Seldom
(3) Never

4-You feel many persons younger to you are brighter and capable than you.
(1) Often
(2) Seldom
(3) Never

5-You feel you are not the studious type
(1) Often
(2) Seldom
(3) Never

6-You feel your parents should allow you more freedom.
(1) Often
(2) Seldom
(3) Never

7-You think that the subjects taught in the schools should be made more interesting.
(1) Often
(2) Seldom
(3) Never

8- You feel your parents still treat you as a baby not showing respect for your individuality.
(1) Often
(2) Seldom
(3) Never

9- You feel your parents do not take adequate interest in your future.
(1) Often
(2) Seldom
(3) Never

10 -You feel there should be more extracurricular activities in the school.
(1) Often
(2) Seldom
(3) Never

11- You feel that life is full of difficulties and problems.
(1) Often
(2) Seldom
(3) Never

12- You feel that your teachers are not good at teaching.
(1) Often
(2) Seldom
(3) Never

13-You think that if a person fails in an examination two or three times; he would do well to stop trying further.
(1)Often
(2) Seldom
(3) Never

14-You feel that your teachers show partiality to some students.
(1) Often
(2) Seldom
(3) Never

15 -You feel that on the whole you are unlucky in many respects.
(1) Often
(2) Seldom
(3) Never

16-You hesitate to approach to your teacher to get your doubt clear.
(1)Often
(2)Seldom
(3) Never

17-You think that your family will not support you if you get into any trouble.
(1)Often
(2) Seldom
(3) Never

18-You feel your brothers and sisters have been morally superior to you.
(1) Often
(2) Seldom
(3) Never

19-You think that you do not have sufficient study facilities at home.
(1)Often
(2) Seldom
(3) Never

20 -You feel that the appearance and surrounding of your home are not so good as you like to be.
(1)Often
(2) Seldom
(3) Never

21-You hesitate to meet your teachers in connection with your personal problems.
(1)Often
(2) Seldom
(3) Never

22-You get the feeling that you have committed many sins.
(1)Often
(2) Seldom
(3) Never

23-You feel that many of your classmates do not understand you.
(1)Often
(2) Seldom
(3) Never

24-You have many difficulties in understanding the teaching in your class.
(1)Often
(2) Seldom
(3) Never

25 -Your parents put too many restrictions on you.
(1) Often
(2) Seldom
(3) Never

26-Your parents oppose your mixing with some of your friends.
(1)Often
(2) Seldom
(3) Never

27-You find life full of sorrow and difficulty.
(1) Often
(2) Seldom
(3) Never

28-You think your classmate do not get along with you well
(1)Often
(2) Seldom
(3) Never

29-You feel that your parents are responsible for many of your difficulties.
(1)Often
(2) Seldom
(3) Never

30- You get discouraged easily.
(1) Often
(2) Seldom
(3) never

\section{REFERENCES}

[1] Banoo J. et al. Comparative Study of Differently Abled Adolescents on Visual Impairment and Physical Deformity on the basis of their Home, Social, School and Emotional Adjustment. Egyptian Nursing Journal, 2017;14(2), 70-77

[2] Chaudhari N. and Phogat, D. A study of adjustment of visually challenged adolescents in relation to their anxiety and degree of impairment, International Research Journal, 2010; 1(11): 22-23.

[3] Daryl R T and Keziah L. ,Adjustment to Vision Loss in a Mixed Sample of Adults with Established Visual Impairment, Investigative Ophthalmology \& Visual Science ,2012, 53, 7227-7234

[4] Registrar General of India Census of India. 2011. Cited from: http://www.censusindia.net.

[5] Daniel K. Psychological Assessment of Visual Impaired Children in Integrated and Special Schools. Education,2012; 2(1): 35-40 Retrieved April 3, 2016 from PDF DOI:10.5923/j.edu.20120201.07

[6] Gill S. Emotional, Social and Educational Adjustment of Visually Handicapped Students of Special Schools students. International Journal of Scientific and Research Publications. 2014, 4(3). 1-4

[7] Gahlawat S. A study of personality and mental health of visually challenged and normal adolescents, International 
Journal of Advanced Education and Research.2017; 2(4), $55-57$

[8] Kumar S. Singh J.;Emotional intelligence and adjustment among Visually Impaired and sighted school students. Asian Journal of Multidimensional Research. 2013; 2(8):1-8.

[9] Lakshmi H.V Geeta C.V. Murthy K.N., Parental perspective towards the education of visually impaired children,Asia Pacific Disability Rehabilitation Journal 2009’20(2)

[10] Mittal,S.R.; Implication of Blindness on Cognitive Development; Unit -02; Instructional Method SESV - 03 MP Bhoj Open University Bhopal;2001,31 -34.

[11] Mishra V. a study of self-concept in relation to ego-strength of sighted and visually impaired students, International Journal on New Trends in Education and Their Implications January 2013 4,(1):203-207

[12] National sample survey organization(NSSO);Disabled persons in India; ministry of statistics and program me implementation, government of India;2002

[13] Panda;K.CEducation of Exceptional Children. Vikash Publishing House Pvt.New Delhi; (1997), 117-119.

[14] Pandey; S.N. \& Pandey; R.K "A Comparative Study of Adjustment of Visually impaired and Sighted Adolescents." Shakshik Parisamvad (An international Journal of Education AAEB.H.U) Banaras Hindu University Varanasi .2013;33(1)-73-76

[15] Pandey; R.K “A Comparative Study of Adjustment of Visually impaired and Sighted Adolescence." Unpublished M.Ed.(Spl.VI) Dissertation Faculty of Education Banaras Hindu University Varanasi .2010

[16] Pant P, Joshi PK. A Comparative Study of Emotional Stability of Visually impaired students studying at secondary level in inclusive setup and special schools. Journal of Education and Practice. 2016; 7(22):53-58.

[17] Pradhan, S.K. .Personality characteristics of visually impaired students in inclusive and special schools. Ambikeya: Journal of Education, 2010,1(2), 25-29

[18] Parua, R.K. , Emotional development of childeren with visual impairement studing in integrated and special school,internatinal journal of advanced research,2015,3(12),1345-1348.

[19] Dutta P.,\& Talukdar J. The impact of vision impairment on students' self-concept; international Journal of Inclusive Education, 2016;20(6) ,659-672

[20] Rajkonwar S, Dutta J, Soni JC. Adjustment and Academic Achievement of Visually Handicapped School Children in Assam International Journal of Science and Research (IJSR). 2015; 4(4)

[21] Rani R. A Study of Academic Anxiety of Visually Impaired Students in Relation to Their Academic Achievement, Journal of Rehabilitation Council of India, 2010,6, (1 \& 2), 61-67.

[22] Rani, R. Emotional intelligence and academic achievement of visually disabled students in integrated and segregated schools, Disabilities and Impairments, 2011;25(1 \&2), 44-50

[23] Reema, A study of relationship between self-concept and adjustment of visually impaired adolescents studying in inclusive and special schools, Ph.D. (Education). Jamia Millia Islamia, New Delhi;2010

[24] Rukwaro, R.N. "The Education Concept of Low Vision Interventions: The Kenyan Model;2006;Retrieved April 3, 2016 from http://www.icevi.org/publications/icevi_wc2006/12 low v ersion/Posters/afr_025_rukwaro.

[25] Singh M., Education of Children With Special Needs Knishka Publication ;New Delhi;2010; 09-10

[26] Singh M and Mishra S; Adjustment to Vision Loss in a Mixed Sample of Adults with Established Visual Impairment, international Journal of Information Research and Review; 2016; 03(04):2098-2101.

[27] The Right of Person With Disabilities Act, The gazette of India; Ministry of law and justice;2016;59,33-34.

[28] Were, C.M.; Indoshi, F.C.; John,A.Y Gender difference in self-concept and academic achievement among visually impaired pupils in Kenya, Educational Research,2010;1(8): 246-252. 